\title{
OS PORTUGUESES ATRAVÉS DO ATLÂNTICO DO SÉCULO XIX AO XXI: POLÍTICAS MIGRATÓRIAS, O SENTIMENTO DE IDENTIDADE E SUAS TRANSFORMAÇÕES
}

\begin{abstract}
Maria Christina Siqueira de Souza Campos ${ }^{I}$
Resumo: Durante três séculos o Brasil foi colônia de Portugal e, a partir do século XIX, os portugueses começaram a aportar na antiga colônia como imigrantes em busca de melhores condições de trabalho, ao lado de outros grupos europeus, incentivados por certa visão espalhada que pretendia o branqueamento da "raça" brasileira. Esse fluxo se acentuou a partir de 1870, quando a cultura do café se espalhou pelo assim chamado "Oeste" do Estado de São Paulo. Passaram a trabalhar juntamente com colonos de outras etnias, o que levou ao desenvolvimento de um sentimento ambíguo de identidade, isolados que estavam em relação à pátria de origem. No século $\mathrm{XX}$ a situação se inverteu: a crise do café em 1929 e o desencadeamento dos processos de urbanização e industrialização na pátria de adoção bem como a restrições à imigração por parte do novo governo ditatorial levaram a uma modificação bem perceptível tanto na forma de trabalho (de colonos passam a comerciantes, principalmente) como da expressão da identidade, o que tendeu a oscilar de acordo com os diversos fluxos migratórios dos séculos XX e início do XXI.
\end{abstract}

Palavras-chave: Imigração portuguesa em São Paulo. Associativismo. Problemas da continuidade das obras luso-brasileiras.

Abstract: For three centuries, Brazil was a colony of Portugal, and from the nineteenth century, Portuguese people began to contribute in the former colony as immigrants seeking better working conditions, encouraged, among other European groups, by those who aimed at lightening the Brazilian 'race'. This flow was accentuated after 1870, when the coffee culture has spread around the so-called "West" of the state of São Paulo. They began to work along with settlers from other ethnic groups, which led to the development of an ambiguous sense of identity, as they were isolated in relation to the country of origin. In the twentieth century the situation was reversed: the coffee crisis in 1929 and the outbreak of the processes of urbanization and industrialization in the adoption country as well as restrictions on immigration from the new dictatorial government led to a very noticeable change much in the way of work (from rural workers they moved to traders, mainly) as of identity expression, which tended to fluctuate according to the various migratory currents of the twentieth and early twenty-first.

Professora associada da Faculdade de Economia, Administração e Contabilidade de Ribeirão Preto da USP e pesquisadora do Centro de Estudos Rurais e Urbanos. Áreas de publicação: sociologia da família, sociologia das migrações, administração municipal e administração da saúde. E-mail: mccampos@usp.br 
Keywords: Portuguese migration in São Paulo. Associativism. Problems related to the continuity of Portuguese deeds.

\section{INTRODUÇ̃̃̃}

Este trabalho é resultado de uma longa pesquisa de caráter sociológico, levada a efeito inicialmente no interior do Estado de São Paulo e posteriormente na cidade de São Paulo, com o objetivo de apreender como se formou e as formas como se expressa hoje a identidade dos portugueses imigrantes nesse Estado, tendo como fontes metodológicas entrevistas coletadas com base na História Oral, bem como a análise de estudos já publicados sobre a formação da região de Ribeirão Preto $^{2}$, a consulta aos $\operatorname{arquivos~existentes~}^{3} \mathrm{e}$ a visita às associações por eles criadas. Inicialmente, é explicada no texto a visão sociológica sobre identidade, identidade étnica e memória que embasou a interpretação dos dados. Em seguida apresenta-se de modo sucinto a história de Portugal no que se refere às navegações que empreendeu a partir do século XV e a ocupação das terras que foi conquistando até a perda de seu império. A emigração que sempre caracterizou a nação lusitana é analisada no que se refere aos fluxos dirigidos ao Brasil, sendo discutidas especialmente a primeira leva para o interior do Estado de São Paulo e as que se fixaram na capital paulista com base no estudo das associações fundadas pelos imigrantes portugueses ao longo do século XX.

\section{IDENTIDADE E MEMÓRIA, UMA VISÃO SOCIOLÓGICA}

O conceito de identidade tem sido trabalhado por muitos cientistas sociais e psicólogos. É um conceito básico da Teoria da Personalidade, orientada pela psicanálise. Sociologicamente, pode-se dizer que se refere a um resultado específico da mediação entre indivíduo e sociedade por meio do processo de socialização, isto é, dos processos correntes da identificação social do indivíduo com os papeis que lhe são atribuídos, de um lado, e por sua expressão diante do ambiente social em cada situação, de outro. A identidade leva o indivíduo a procurar produzir uma relação equilibrada entre sua identidade pessoal - a saber, entre a estrutura de suas experiências pessoais e aquilo que está solidamente impregnado - e sua identidade social - ou seja, as estruturas de comportamento que lhe são exigidas pelas expectativas de papeis. Isso quer dizer que, apesar de sua singularidade, o indivíduo não pode se isolar da comunicação e da interação com os outros

\footnotetext{
Ribeirão Preto é uma cidade de tamanho médio na região norte do Estado de São Paulo, que foi o centro do desenvolvimento do café nas últimas décadas do século XIX e início do século XX.

3 Os arquivos consultados foram os de Ribeirão Preto (o Arquivo Municipal e o da Associação Comercial e Industrial), Franca e Sertãozinho.
} 
como também não pode se submeter totalmente às imposições das expectativas sociais já existentes ou a elas se deixar acomodar. Assim, a identidade permite ao indivíduo tanto se identificar com seus papéis sociais e se engajar neles como atuar diante deles com autonomia (HARTFIEL, 1972). O conceito de identidade descreve, pois, a representação cognitiva da percepção de continuidade da própria pessoa sendo o autoconceito o resultado da avaliação da concordância de vetores de ação efetivamente utilizados com os próprios critérios.

Ampliando-se o conceito de identidade na direção da identidade étnica, vê-se que este último tem sido utilizado com referência tanto a estados de consciência subjetivos como a modos de comportamento observáveis. Autores como Nóvoa (1992) e Hall (1997) têm visto a identidade étnica como sendo um processo identitário e não como algo constituído ou naturalizado. Lévi-Strauss (1987) chegou a afirmar que o conceito de identidade não deveria ser construído sobre uma fundamentação empírica, mas simbólica e cultural, mas não se adota essa visão neste estudo.

Hall (1997, p. 67) define etnia como as "características culturais língua, religião, costumes, tradição, sentimento de lugar - que são partilhados por um povo". Prosseguindo em suas considerações, diz que a identidade étnica vai se reconstruindo e reconfigurando ao longo do processo histórico, não havendo possibilidade de entendê-la como algo dado, definido definitivamente desde o começo da história de um povo. A projeção dos membros de um grupo nas identidades culturais, ao mesmo tempo em que são internalizados seus significados e valores, tornando-os parte de cada um, tem com consequência vincular os próprios sentimentos subjetivos aos lugares objetivos que ocupam no mundo social e cultural (HALL, 1997).

Tanto Michel Pollak (1992) como Marieta de Moraes Ferreira (1997) enfatizam a impossibilidade de se falar de identidade e identidade coletiva sem abordar a questão da memória. Segundo Pollak (1992), os acontecimentos vividos pessoalmente vão constituir a memória individual e a coletiva. Mesmo sem tê-los vivenciado pessoalmente, o indivíduo os vivencia 'por tabela', pois participa do grupo onde ocorrem tais acontecimentos. A memória é um fator fundamental do sentimento de continuidade e de coerência de uma pessoa ou de um grupo, enquanto se reconstrói. Mas essa reconstrução implica mudanças, negociações e transformações na interação com os outros. No caso da memória herdada (por meio da transmissão familiar e escolar), concorda-se com Pollak (1992) de que há uma relação estreita entre a memória e o sentimento de identidade, aquela imagem que a pessoa adquire, ao longo de sua vida, referente a ela própria, a imagem que constrói e passa aos outros e a si própria, de modo a haver concordância entre a maneira como se percebe e os outros a percebem. Como salientou, na construção da identidade há três elementos essenciais, ou seja, a unidade física - no caso pessoal, o próprio corpo e, no caso coletivo, as fronteiras de 
pertencimento ao grupo -, a continuidade no tempo - em sentido físico, psicológico e moral - e o sentimento de coerência - os diferentes elementos que formam o indivíduo constituem uma unidade. Em conclusão, segundo Pollak, a memória é um elemento constituinte do sentimento de identidade (1992, p. 204). Assim, a reconstrução do passado sempre é feita com os olhos e os valores do presente, com base nas experiências de vida do narrador. "O documento criado pela recuperação da memória é um documento do presente, sendo, contudo, uma reconstrução de fatos passados" (LANG; CAMPOS; DEMARTINI, 1998, p.14). Foi com base nessa visão que foram coletados e analisados os relatos orais de imigrantes portugueses e seus descendentes.

Ferreira (1997) acentua que a memória constitui um elemento importante para o reconhecimento e valorização dos grupos. E a autora acrescenta que "mesmo a memória constituída efetua um trabalho de manutenção, de renovação, de coerência, de unidade, de continuidade, de organização." (p. 157). Ainda essa historiadora salienta, com base em Pollak, que entende por identidades coletivas "todos os investimentos que um grupo deve fazer ao longo do tempo, todo o trabalho necessário para dar a cada membro - quer se trate de família ou de nação - o sentimento de unidade, de continuidade e de coerência de pertencimento." (p.158). E, referindo-se ao foco de suas considerações no texto, as comemorações, Ferreira destaca que estas são um elemento central da construção da identidade e isso será fundamentado mais adiante, ao se tratar da realidade vivenciada pelos portugueses em São Paulo.

Uma autora que tem se dedicado profundamente aos estudos migratórios parte de uma reflexão interessante sobre identidade e alteridade: trata-se da socióloga portuguesa Maria Beatriz Rocha-Trindade (2006), que chama a atenção para o crescente interesse nos tempos atuais pelos estudos sobre identidade, devido à consciência atual do direito à diferenciação e à afirmação cultural de grupos e comunidades minoritárias. Como Rocha-Trindade salienta em seu texto (2006), na base de tal consciência estão dois conceitos em oposição, identidade e alteridade, isto é, o sentimento de cada um de que pertence a um determinado grupo e seu reconhecimento de que existem outros grupos, diferentes dele. Assim, nos tempos atuais, são frequentes os grupos multiétnicos, multiculturais e ideologicamente distintos, em virtude dos deslocamentos humanos, que podem ser por um tempo determinado ou de natureza mais permanente, como os movimentos migratórios.

Quando se pensa em fluxos migratórios e integração de imigrantes em novos espaços de vida, não se pode deixar de considerar o conceito de identidade coletiva. Corsten (1999 apud DOMINGUES, 2002) trabalhou essa ideia, destacando que as gerações existem como "identidades coleti- 
vas" e estas se constroem com base nas experiências comuns, por meio das interações com outras gerações, para delas se distinguirem.

Outro sociólogo português que traz uma contribuição relevante para o presente estudo é Boaventura de Sousa Santos, abordando a questão das identidades culturais. Santos (1994) salienta o que, aliás, os autores anteriormente tratados já tinham feito, que é a inexistência de regras a esse respeito. As identidades culturais não são rígidas ou imutáveis, resultando sempre de um processo de identificação próprio de cada momento ou situação. Essas identidades se descontextualizam e se recontextualizam continuamente, num processo que tem por base conflitos e confrontos, bem como negociações com outras identidades.

Quando trata da identidade portuguesa em particular, B. S. Santos (1995) traça um quadro realista de Portugal e sua cultura, mostrando como as contradições dominam não só as imagens que seu povo faz de si próprio como as que os outros povos que entram em contato com o país fazem do mesmo. Afirma que a cultura portuguesa é muito heterogênea, devido ao tipo e historicidade do seu nível de desenvolvimento intermédio, traduzindose esse traço em representações sociais discrepantes, em que o povo aparece como sendo capaz de se adaptar a todas as coisas e ocupando predominantemente uma posição de economia agrária por excelência. Por séculos, Portugal foi o centro de um grande império colonial e, ao mesmo tempo, a periferia da Europa. Santos chega ao ponto de levantar a hipótese de que não existe propriamente uma cultura portuguesa em termos de conteúdo, mas somente em termos de forma. Sua visão é de que a cultura portuguesa não se diferencia suficientemente das outras externas a ela, evidenciando traços de uma extrema heterogeneidade, o que o leva a afirmar que existe, ao mesmo tempo, um déficit de identidade pela diferenciação e um déficit de identidade pela homogeneidade. Disso decorre, entre outras características, o cosmopolitismo e seu outro lado, o acentrismo, caracterizado pela multiplicação sem fim dos localismos.

Em trabalho mais recente de Maria Beatriz Rocha-Trindade sobre o regionalismo em Portugal (2009), pode-se encontrar a fundamentação do que Boaventura de Sousa Santos afirmou sobre a cultura portuguesa. A autora estuda os migrantes de três concelhos da região da Cordilheira Central portuguesa que se deslocaram para a cidade grande à procura de trabalho e melhores condições de vida. O regionalismo se torna evidente tanto no fato de procurarem se instalar em Coimbra em local próximo ao lugar de moradia de seus conterrâneos que haviam emigrado anteriormente como na busca de um trabalho semelhante ao que já desempenhavam na aldeia de origem. A proximidade daqueles oriundos de sua própria terra tem como efeito não só a possibilidade de contarem com a solidariedade destes como também a criação de associações regionais que os congregam e contribuem para o apoio aos novos chegados à cidade grande, dando ensejo à participa- 
ção em diversos eventos festivos, especialmente na aldeia de origem para onde retornam para comemorações profanas e religiosas significativas.

\section{Portugal e a EMigração}

O grande império que Portugal construiu a partir do século XV abrangeu terras na África, Ásia e na América. As medidas de controle de um império que se estendia de Lisboa a Malaca (Malásia) eram muitas, entretanto, para um país pequeno como Portugal. A expedição para Ceuta, em 1415, realizada por D. João I (1385-1433), é considerada o início do império português. Após essa expedição, muitas outras foram realizadas pelas caravelas de D. Henrique, o Navegador, quinto filho de d. João I. O primeiro período do Império (1415-1460) foi centralizado no Atlântico. As ilhas da Madeira e de Porto Santo foram colonizadas por duas expedições em 14191420, por iniciativa de João Gonçalves Zarco, Tristão Vaz Teixeira e Bartolomeu Perestrelo. As dos Açores foram descobertas em 1427, por Diego Silves. Entretanto, as descobertas ao longo da costa africana foram realizadas mais lentamente, tendo sido os portugueses os primeiros a avançarem sistematicamente por essa região. Entre os anos de 1450 e 1460 foram encontradas e colonizadas as ilhas do Cabo Verde. De 1460 a 1500 foram se estabelecendo duas rotas principais de exploração, uma em direção do oriente, outra para o ocidente. Pelos anos de 1460, data da morte de D. Henrique, a costa da África já havia sido explorada até a Libéria. O anseio por novas descobertas, após um período de certo desinteresse, somente foi restabelecido com D. João II (1481-1495). Com ele foram alcançados o Congo e Angola e, em 1488, Bartolomeu Dias atingiu o Cabo da Boa Esperança (ENGERMAN; NEVES, 1997).

No início do processo migratório, as ilhas dos Açores e da Madeira tornaram-se uma importante fonte de emigração, assim como o território de Portugal, processo esse que se iniciou no final do século XV, na época dos grandes descobrimentos. Já na segunda metade do século XV levas de indivíduos começaram a deixar Madeira e os Açores, seguindo alguns para as Canárias e a África, mas a maioria para o Brasil. Nesse período Portugal chegou a criar até incentivos para manter pessoas nos Açores. Desde 1630, o interesse pelas ilhas do Atlântico Norte se reduziu bastante e a maioria dos migrantes passou a ir para o Brasil (ENGERMAN; NEVES, 1997).

Essa fase marcou o início do maior império colonial do mundo, que terminou apenas no século XX. Na fase do seu apogeu do império, que vai até meados do século XVI, Portugal tinha menos de 300 navios. Pouco após a morte de D. João II, foi descoberto o caminho para as Índias. O período conhecido como a primeira Era do Ouro do império português vai de 1500 a 1580, durante o qual predominou o comércio com a India, mas já no período que vai de 1580 a 1660 era possível perceber certa decadência que foi 
seguida de recuperação ao conseguir se libertar do jugo espanhol, não se devendo esquecer que de 1580 a 1640 o Estado português esteve sob o domínio da coroa espanhola e, consequentemente, foi alvo de ataques dos inimigos da Espanha, especialmente os holandeses. O resultado final foi a vitória destes no Leste da África e a vitória dos portugueses no Brasil. A razão de ter sido mantido o império explica-se pelas profundas raízes culturais e pessoais que os portugueses estabeleceram nas regiões colonizadas, nas quais a influência dos missionários era claramente sentida.

Após 1640, Portugal, já novamente independente, começou a reorganizar suas propriedades e relações coloniais. Com a introdução do cultivo da cana no Brasil, o açúcar passou a ser o principal produto brasileiro, tendo sua produção mudado a face de sua colônia até a descoberta do ouro em Minas Gerais no final dos anos de 1690. O Brasil passou a ser o novo centro, o que marcou o início de uma nova era de ouro (1660-1822), caracterizada pela riqueza oriunda da mineração aurífera e, quando esta se extinguiu, novamente do sucesso do cultivo da cana e da produção do açúcar. Mas a perda de influência portuguesa era evidente na segunda metade do século XVII. Havia, entretanto, algumas diferenças importantes em relação ao século XVI. A principal delas era de que no Brasil, diferentemente da China, não havia uma grande população de nativos para competir com os novos colonizadores. Isso permitiu a construção de uma sociedade colonial notadamente independente. Em 1725 o centro econômico do império mudou-se de Goa para São Salvador da Baía. Mesmo durante o período da riqueza de Portugal, é difícil avaliar se o esforço humano envolvido em tantas conquistas foi compensado pelos ganhos auferidos. Além dos fluxos econômicos, é preciso destacar os aspectos religiosos e culturais da expansão portuguesa, que foram muito importantes, especialmente no que se refere aos missionários trazidos pelos colonizadores, que se tornaram uma das mais importantes forças condutoras do império.

Em 1822, a perda da grande colônia que se tornou independente prejudicou muito a situação de Portugal. O antigo e imenso império foi reduzido a pequenos pontos, com os principais centros em Angola, Moçambique, Goa, Macau e Timor. A riqueza proveniente das colônias era de vital importância para a metrópole, que vivia uma séria crise econômica e um componente essencial para a política doméstica. Novas políticas foram estabelecidas, mas sem estratégias coerentes e de pouco sucesso, impedindo o desenvolvimento de uma nova era de ouro. Eulália Maria Lahmeyer Lobo (2001) observa que o modelo econômico da monarquia liberal levava a fortes pressões sobre a balança de pagamentos, $\mathrm{o}$ que resultava em crescente dívida externa, com o aumento das exportações, até para o Brasil, e as remessas de poupanças dos cidadãos lusitanos que estavam estabelecidos neste país (p. 15). 
A emigração portuguesa ocorrida no século XIX dirigiu-se para o Brasil principalmente e, no século XX, dirigiu-se preferencialmente ao Brasil até a década de 60, a partir de quando começou a diversificar seus destinos. Os anos após 1961 marcam o período em que Portugal perdeu definitivamente seu império. O principal destino dos imigrantes, então, passou a ser a Europa ocidental (França, Alemanha e Suíça) que, tendo superado as dificuldades e miséria ocasionadas pela II Grande Guerra, estava em pleno desenvolvimento e necessitava de mão-de-obra para a reconstrução do que havia sido destruído durante a guerra. Também a América do Norte atraía os portugueses, sendo os EUA e o Canadá os destinos preferidos. Depois de 1974, ano da Revolução dos Cravos, acentuou-se também o declínio da emigração de forma significativa, iniciando-se um fluxo contrário, no sentido do retorno de muitos emigrantes. Isso se acentuou após a entrada de Portugal na União Europeia, na década de 80. Um dado interessante, entretanto, mostra a principal herança do maior império colonial do mundo. Enquanto a população de Portugal era de cerca de 10 milhões de habitantes no fim do século XX, aproximadamente 200 milhões de pessoas no mundo falavam português (ENGERMAN; NEVES, 1997).

As leis portuguesas apresentam uma atitude ambígua e cambiante em relação à emigração. Em alguns casos houve a promoção da emigração e colonização, em outros, especialmente $m$ períodos de intensos fluxos de saída de emigrantes, foram criados meios para controlar a saída. Ainda em outros casos, o rei limitava e promovia a emigração ao mesmo tempo. No século XVIII as leis tentaram reduzir a "corrida ao ouro" de Minas Gerais, no Brasil, ao mesmo tempo em que tentavam promover a colonização do Rio Grande do Sul e Santa Catarina, também no Brasil. No século XIX, a Constituição portuguesa de 1838, em seu título III, determinava a liberdade migratória tendo sido assim estabelecido: "Todo Cidadão pode conservar-se no Reino, ou sair dele e levar consigo os seus bens, uma vez que não infrinja os regulamentos da polícia, e salvo o prejuízo público ou particular." (LEITE, 1999, p. 179). Assim, os emigrantes podiam sair do país desde que tivessem um passaporte, que custava cerca de $10 \%$ do valor da passagem de navio para o Brasil em terceira classe. ${ }^{4}$

O CAFÉ E O INÍCIO DA GRANDE IMIGRAÇÃO NO BRASIL

O café começou a se desenvolver no Brasil no século XIX, a partir das lavouras do Vale do Paraíba fluminense e depois paulista. Nessas la-

Lobo (2001) indica que essa passagem custava, até 1912, 55.800, quando foi reduzida para 22.000, por sugestão das autoridades portuguesas, interessadas em dar solução à questão da falta de terras suficientes no Norte do país para poder alimentar a população (p.20). A ideia proposta foi de que os navios que levavam emigrantes trouxessem carga na volta, o que propiciaria ganhos nos fretes, possibilitando a redução no preço da passagem. 
vouras mais antigas foi utilizada preponderantemente a mão-de-obra escrava. Mas o aumento do preço dos escravos e os gastos de subsistência com os mesmos fizeram com que a mão-de-obra escrava propiciasse menor rentabilidade em comparação à assalariada.

Se a introdução do trabalho assalariado foi um marco importante na consolidação do regime capitalista no setor agrário brasileiro, foi também o mais importante problema social do Brasil no século XIX. A região do Oeste paulista - que se abre em leque desde Campinas para o Noroeste, alcançando Rio Claro e se estendendo até Bauru e Ribeirão Preto -, foi a que teve o mais rápido crescimento econômico e populacional a partir de 1850, aproximadamente (DEAN, 1977). Para solucionar esse que era um dos grandes problemas enfrentados pelos cafeicultores, a escassez de mão-de-obra, tanto no que se refere ao cultivo como ao beneficiamento do café, foram tomadas medidas diferentes. Para o primeiro, a solução foi o incentivo à imigração europeia, enquanto que, para o segundo, tentou-se substituir o braço humano por maquinários apropriados. De acordo com Stolcke (1986, p.18),

\footnotetext{
o desenvolvimento e a organização da força de trabalho livre destinada às fazendas de café de São Paulo foi um processo ao mesmo tempo econômico e político determinado pelo confronto entre os interesses econômicos dos fazendeiros e a habilidade dos trabalhadores para resistir às imposições dos fazendeiros.
}

Antes da abolição dos escravos (1888), quando já se formavam as fazendas de gado e posteriormente de café na região de Ribeirão Preto, havia indícios da presença de escravos na região, trazidos de outras áreas do Oeste paulista e de Minas Gerais. Mas Martins (1986, p.14) chama a atenção para o fato de que "...a transformação das relações de trabalho na cafeicultura originou-se na esfera da circulação, na crise do comércio de escravos, que produziu os seus efeitos mais drásticos no Brasil a partir de 1850 , quando o tráfico negreiro foi definitivamente proibido..." O regime de trabalho adotado com o trabalhador imigrante era o do colonato, que se caracterizou pela combinação de três elementos: pagamento fixo pelo trato do cafezal; pagamento proporcional pela quantidade de café colhido e permissão para a produção direta de alimentos pelos imigrantes visando ao próprio sustento e comercialização do excedente (MARTINS, 1986). O colonato não era um trabalho individual, tendo sido inserido no mundo do trabalho pela contribuição da força de todos os membros da família: marido, mulher e filhos. Os principais grupos que chegaram na segunda metade do século XIX eram constituídos por italianos, em maior quantidade, seguidos em número pelos espanhóis e portugueses. Os imigrantes europeus eram mais bem recebidos, já que, segundo uma ideologia bastante espalhada nessa época, "contribuíam para branquear a raça brasileira". A introdução da mão-de-obra livre, em suas várias formas de trabalho (parceria e 
assalariamento, com remuneração mensal ou por tarefa) possibilitou a expansão de uma economia moderna, com base no contínuo avanço tecnológico, permitindo superar o estrangulamento da economia colonial. Para isso contribuíram, significativamente, a política de imigração adotada a partir da década de 80 do século XIX, com subvenção estatal da vinda de estrangeiros para trabalhar na agricultura cafeeira, e a penetração da ferrovia, que veio acompanhando a expansão cafeeira e se tornando, ao mesmo tempo, um fator importante de seu crescimento. No último quartel do século XIX já tinha sido ultrapassada a fase de gestação da economia cafeeira, que se tornou capaz de financiar a própria expansão.

Devido aos muitos conflitos ocorridos entre fazendeiros e colonos imigrantes, em decorrência dos maus tratos que muitas vezes aqueles impunham aos últimos, os cafeicultores procuravam impedir que imigrantes de uma mesma procedência ficassem próximos. Também a grande distância entre as propriedades ocasionava a dispersão desses imigrantes, o que, sem dúvida, não favoreceu reuniões nem formação de grupos para a defesa de seus direitos e interesses. No interior da propriedade, o fazendeiro vigiava e impedia o surgimento de quaisquer tipos de agrupamento (QUEIROZ, 1978, p. 39).

Pode-se dizer que a grande imigração, nos moldes como vinha se processando desde os finais do século XIX, terminou em 1930. A crise de 1929 levou à bancarrota de grande número de cafeicultores, cujas propriedades foram levadas a leilão e loteadas. Muitos imigrantes conseguiram assim ter acesso à propriedade da terra, outros rumaram para as cidades próximas e adquiriram um pequeno comércio. Foi o que aconteceu com muitos portugueses, como mostra o trabalho de Merlotti e Campos (2000).

\section{O desenVolvimento e os novos fluXos migratórios de Portugal}

Em dezembro de 1930, o decreto-lei federal nº 19.482 já colocava restrições à migração externa para o Brasil, o que foi ampliado pelos decretos 24.215 e 24.258 de 1934. Com a Constituição de 1934, foi introduzido o regime de quotas - a corrente imigratória de nenhum país poderia exceder anualmente o limite de $2 \%$ do número total dos respectivos nacionais estabelecidos no Brasil nos últimos cinquenta anos - restringindo, assim, consideravelmente a imigração estrangeira no Brasil (artigo 126, parágrafo 6) (NEIVA, 1949 apud ARAÚJO FILHO, 1956). Essa legislação foi ainda mais endurecida com o decreto-lei $\mathrm{n}^{\circ} 3175$, de $7 / 4 / 41$, ao suspender a concessão de vistos temporários e permanentes para a entrada de estrangeiros no Brasil, com exceção dos concedidos a portugueses e nacionais de estados americanos e os casados com brasileiros (as) natos(as) ou com filhos brasileiros e por serem especialistas ou por disporem de capitais que pudes- 
sem contribuir para o desenvolvimento econômico do país ${ }^{5}$. Os portugueses, particularmente, decresceram muito em quantidade no período considerado.

Novo fluxo imigratório português para o Brasil ocorreu na década de 1950 até 1963, sendo os imigrantes então atraídos pela expansão econômica do país nessa época. Em 1964, com a instalação do regime militar no Brasil a situação mudou bastante. Várias medidas restritivas cercearam a liberdade, introduzindo o controle dos meios de comunicação e a perseguição aos considerados de esquerda. Nessa ocasião voltou a se interromper a imigração portuguesa com a mudança de destino: a Europa, já recuperada após a Segunda Grande Guerra, estava em plena expansão e necessitava de mãode-obra, o que a fez se tornar o rumo preferido dos portugueses, do mesmo modo como de outras populações mediterrâneas.

No Brasil, somente por volta de 1985 a ditadura militar começou a se abrandar e o poder foi sendo passado aos poucos a civis. Essa data coincidiu com a chegada de diversas empresas portuguesas desejosas de se instalarem no Brasil, o que trouxe novos fluxos de imigrantes portugueses. Dessa vez, entretanto, tratava-se de pessoal qualificado de nível superior, que vinha ocupar cargos graduados dentro dessas empresas. Um exemplo desse processo é a Portugal Telecom, que estabeleceu acordos de cooperação com parceiros estratégicos, haja vista a aquisição de $1 \%$ do capital social da Telefônica e sua participação no sistema Telebrás que se tornou realidade em 1998 com os investimentos no mercado brasileiro de telecomunicações, com a aquisição de participações importantes na Telesp Celular, Telesp Fixa e CRT (Companhia Riograndense de Telecomunicações), que apresentavam condições muito favoráveis de crescimento.

Com o agravamento da situação econômica europeia e seus reflexos em Portugal, no início do século XXI, novas levas começaram a partir para o Brasil, seja com contrato de trabalho já assinado antes da partida, seja vindo em busca de postos de trabalho. Mas, com a formação mais qualificada de que os "novos imigrantes" dispunham e com o apoio do Consulado de Portugal e da Câmara Portuguesa de São Paulo, suas condições passaram a ser bem melhores se comparadas com as dos antigos imigrantes, que vinham somente com uma carta de chamada, embarcados em navios que demoravam razoável tempo para atravessar o Atlântico e aportar no Rio de Janeiro ou em Santos, após uma penosa viagem em terceira classe.

\section{Os portugueses no interior e na capital de São Paulo}

Foram coletados para este estudo depoimentos orais de imigrantes portugueses e seus descendentes com o objetivo de se obterem dados não

5 A respeito da legislação sobre a imigração estrangeira, consultar Camargo (1981, v.1, p. 144 ss.). 
tanto sobre fatos e períodos, mas principalmente sobre sua trajetória de vida e recuperar a memória dos tempos da imigração e do trabalho no país de adoção. Tratando-se, basicamente, de um estudo qualitativo, cuja principal fonte foi a coleta de relatos orais, mais importante que o número de depoimentos colhidos eram sua diversidade e o fato de se ter atingido o "ponto de saturação" (BERTAUX, 1980), o que indica que já se dispunha de informações suficientes sobre um determinado tema e que já não estava vindo à luz mais nada de novo. Como diz esse autor, trata-se de um processo operado no plano da representação que a equipe de pesquisa constrói pouco a pouco de seu objeto de pesquisa, com base nas representações parciais da primeira série de sujeitos encontrados. De acordo com Bertaux (1980), a saturação, quando encontrada, dá uma base sólida para a generalização. Assim, durante a coleta dos relatos orais na região de Ribeirão Preto, não houve preocupação em se selecionar uma amostra representativa do universo, mas em conseguir um número razoável de entrevistados que tivessem disposição e tempo para mergulhar em seu passado e comunicar ao pesquisador o produto de suas reflexões sobre a própria vida. A análise dos relatos orais envolveu tanto a sua forma como seu conteúdo, sempre se levando em consideração a finalidade do documento e a maneira como foi construído. A análise permeou todo o processo de pesquisa, realizando-se concomitante à coleta dos relatos, de modo a permitir introduzir modificações, se necessárias, na proposta inicial.

Como já se explicou na introdução, um dos objetivos deste estudo foi analisar o processo de construção de novas identidades de famílias de portugueses e seus descendentes que vieram tanto para o interior paulista na primeira metade do século passado como daqueles que se dirigiram mais tarde para a capital paulista. Assim, esta parte é de especial relevância para o mesmo, pois permitiu ter uma visão dos portugueses e seus descendentes "por dentro", ou seja, com base em seus próprios relatos, chegar a conhecer seu modo de vida e suas práticas, bem como entender seus valores e representações, tanto a respeito de si mesmos e de sua terra de origem, como do país de adoção e de seus habitantes, os brasileiros.

Foram vinte e cinco os depoimentos realizados no interior de São Paulo, no período de março/1998 a março/2000. Todos vieram para trabalhar no meio rural paulista, em especial na região de Ribeirão Preto. Os entrevistados da primeira geração eram pessoas idosas, com idade variando entre sessenta e oito e noventa e dois anos na ocasião da entrevista. Sua origem foi, principalmente, da zona rural do Norte de Portugal (região do Minho), tendo sido também entrevistado um oriundo da ilha da Madeira. Vieram para o Brasil, atraídos por cartas de chamada de parentes ou amigos que os informavam sobre as novas oportunidades de trabalho ou, ainda, por meio de contratos firmados com os fazendeiros já antes da vinda, recebendo, nesse caso, a passagem do futuro empregador. 
Uma característica comum aos entrevistados da primeira geração, pertencentes ao primeiro grupo de emigração que vai do final do século XIX ao começo do século XX, é ter sido sua saída de Portugal motivada por dificuldades econômicas com a perspectiva de uma melhora de vida no Brasil. Quase todos eram originários do meio rural ou de pequenas aldeias e se dedicavam principalmente à agricultura em terra própria ou de terceiros. Mesmo no caso de serem proprietários da terra onde trabalhavam, o produto não era suficiente para alimentar toda a família, devido ao fato de se tratar de lotes muito reduzidos. É preciso não esquecer que, nesse período, Portugal passava por um período de instabilidade política e econômica e a expansão da agricultura cafeeira os atraiu em larga escala.

Alguns relatos ilustram bem a saga dos primeiros imigrantes encaminhados ao trabalho na agricultura cafeeira. D. Joaquina, a mais idosa imigrante entrevistada, pois já contava noventa e dois anos por ocasião seu relato, veio para o Brasil com quinze anos, junto com os pais e alguns irmãos. Casou-se muito nova, já aos dezesseis anos, um ano após ter se instalado no Brasil. Segundo a entrevistada, as mulheres casavam-se cedo porque, como, na maioria das vezes, iam para as fazendas de café e toda a família (com exceção da mãe) tinha que trabalhar na terra; assim, o casamento era uma forma de as moças escaparem da atividade rural e passarem a se dedicar exclusivamente aos afazeres domésticos e à criação dos filhos. O marido de D. Joaquina era de origem italiana e ela o conheceu na lavoura. Aqui no Brasil a família era bem relacionada tanto com portugueses, que também tinham vindo para trabalhar nessa fazenda ${ }^{6}$, como também com outros grupos de imigrantes, pois, segundo D. Joaquina, a maioria era de origem italiana. Apesar de D. Joaquina ter deixado duas irmãs com filhos em Portugal, afirmou que nunca houve troca de correspondência e que nem sabia se ainda havia algum parente vivo morando lá. Como D. Joaquina não tem boas lembranças de Portugal e perdeu totalmente o contato com seus familiares que lá permaneceram, nunca mais se interessou nem acompanhou notícias relacionadas a Portugal.

Ainda que tenha se expressado com pronunciado sotaque português, reiterou claramente que se sentia brasileira, tendo inclusive se naturalizado. Ela explicou essa decisão pelo fato de ter sofrido muito em Portugal e por isso nem querer saber mais de lá. Nunca mais retornou ao país natal, recusando-se a ir mesmo quando convidada por uma neta. Citando suas palavras: "Deus me livre de Portugal, para mim o Brasil foi tudo. Eu quero estar no Brasil". No entanto, D. Joaquina, até a ocasião da entrevista, usava brincos de argola e, com 92 anos, segundo contou sua filha, às vezes no

\footnotetext{
Essa fazenda onde trabalhou a família de D. Joaquina era de propriedade do "Coronel" Francisco Schmitt, denominado "rei do café" na região. Chegou a ser proprietário de 90 fazendas.
} 
domingo punha o aventalzinho e o lenço na cabeça, bem à moda portuguesa, para poder se dedicar à culinária. Sua filha também contou que a mãe era grande apreciadora do caldo verde e da sopa de polenta com leite e assim costumava lhe fazer esses pratos duas a três vezes por semana. Vê-se, pois, que, apesar de toda a rejeição manifestada em relação ao país de origem, muitas de suas tradições estavam bem impregnadas, mostrando o vínculo com as raízes portuguesas. É um caso típico de identidade e alteridade, mas esta manifestada não em relação à comunidade circundante, mas em relação à origem.

Outra entrevista - feita em vários encontros - é um relato detalhado sobre a imigração portuguesa em Ribeirão Preto, evidenciando a não existência de uma comunidade étnica de origem portuguesa e a não continuidade das tradições e cultura do povo luso no interior paulista. O entrevistado embora figura máxima de representação da comunidade portuguesa na região ${ }^{7}$ - deixou transparecer o próprio distanciamento em relação à cultura lusitana e o ressentimento de sua função ser meramente simbólica no Consulado, já que tinha que enviar a São Paulo, para processamento, toda a documentação que lhe chegava às mãos da parte de portugueses ou de brasileiros desejosos de passar mais tempo em Portugal ou lá trabalhar.

Assim, percebe-se que as condições de vida desses imigrantes, em relativo isolamento na zona rural e de forma misturada com outros grupos imigrantes, contribuíram para que se distanciassem mais rapidamente de suas origens lusitanas, tivessem pouco contato com os parentes remanescentes na terra de origem e passassem mais rapidamente a se sentir brasileiros. Isso não impediu que procurassem educar os filhos nascidos na nova terra de acordo com os valores e padrões morais que tinham recebido de seus antepassados. Todos os entrevistados das gerações já nascidas no Brasil enfatizaram que a honestidade e a religiosidade foram muito acentuadas por seus pais, bem como a importância do empenho no trabalho para o sucesso na vida.

A imigração ocorrida após 1930, chegada à cidade de São Paulo já no segundo período, ou seja, no pré- e pós- Segunda Guerra Mundial, foi desencadeada ora por razões econômicas, ora por divergências políticas, devidas à ditadura de Salazar. Esses imigrantes já dispunham de um nível educacional mais elevado e vieram para se dedicar a atividades urbanas. No início, geralmente se instalavam perto de parentes já residentes na cidade e trabalhavam com eles. Tão logo se sentiam em situação mais estável com alguns recursos amealhados, começaram a trabalhar de forma autônoma - de modo geral como vendedores ambulantes de porta em porta ou

O entrevistado era responsável pelo vice-consulado de Portugal na região nomeado pelo governo brasileiro, mais especificamente pelo Ministério dos Negócios Exteriores do Brasil, para representar os interesses da colônia portuguesa regional. 
como caixeiros viajantes indo e voltando do interior-, ou montaram pequenos negócios próprios (açougues, padarias, lavanderias, entre outros) que lhes permitiram melhorar rapidamente suas condições de vida e guardar recursos para o futuro.

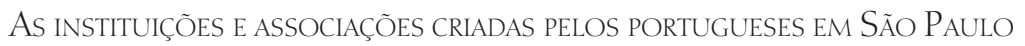

Considerado numa perspectiva da linguagem corrente, o associativismo é a tendência que os indivíduos têm de se agruparem para atingirem objetivos comuns e resolverem problemas, o que seria mais difícil de alcançar individualmente. $\mathrm{O}$ associativismo é certamente uma forma de adquirir capital social que, por sua vez, pode constituir-se em oportunidades de mobilidade social. Há claramente uma vantagem para os imigrantes em se associarem a seus conterrâneos, funcionando as organizações por eles fundadas como redes sociais de auxílio mútuo que extravasam a estrutura familiar ou, como diz Bourdieu (1979), funcionando como fonte de capital social. Esse apoio mútuo acaba por favorecer o sucesso pessoal e possibilita a ascensão social, à medida que permite aos indivíduos melhorar as condições de vida e elevar seu status social (ALBUQUERQUE, 2008).

$\mathrm{O}$ associativismo é um traço forte da cultura portuguesa, também partilhado por outros grupos de imigrantes, mas não na mesma intensidade. Carreiras e Malamud (s.d.) salientam o importante papel das associações tanto na "construção e no reforço de referenciais nacionais de Portugal, uma tendência que a literatura designa como etnicizante, como no seu impacto enquanto veículo de assimilação dos imigrantes aos quadros culturais da sociedade receptora" (p. 97). Fiss (2001, p. 6) ainda acrescenta que "em todo o mundo onde a numerosa comunidade portuguesa se faz presente, está, também, a união em torno da manutenção dos seus valores culturais, da preocupação com a sociabilização e atividades ligadas à área da saúde e da assistência." Conclui dizendo que, no "Brasil, onde a integração dos portugueses é facilitada pelo idioma, as associações são a identificação ainda maior da sua cultura." (idem).

$\mathrm{O}$ associativismo da comunidade portuguesa tornou-se manifesto na cidade de São Paulo desde o início do século XX, quando foram fundadas as primeiras instituições de caráter mais amplo, com exceção da Beneficência Portuguesa, que foi criada em 1859 para dar apoio e tratamento de saúde aos imigrantes portugueses que viviam em condições precárias. O desejo de apoiar os mais necessitados sempre esteve por trás das iniciativas que levaram à fundação da maior parte das entidades da comunidade de origem lusitana. Além disso, a vontade de se reunir, trocar informações sobre a aldeia natal, encontrar os amigos junto com a família, tudo isso deu força aos primeiros imigrantes, que se empenharam efetivamente para reunir recursos e poder concretizar o sonho de se verem representados por uma 
associação forte e de projeção. Essas entidades contribuíram significativamente para a manutenção da identidade portuguesa, mas, mais ainda, para o apego à região de origem. Como salientou Boaventura Sousa Santos (1995), a identidade regional é bem mais acentuada do que a nacional e isso se revela plenamente ao se visitarem as associações regionais e se verem os símbolos pendurados à parede ou colocados em prateleiras em destaque: redes, no caso de aldeias de pescadores, fotos da aldeia, roupas típicas expostas, imagens das caravelas e do padroeiro e, como denominador comum, a imagem de Nossa Senhora de Fátima, padroeira da pátria lusitana e apoio de todos os necessitados.

A elevação do nível de vida levou os imigrantes a pensarem na fundação de entidades que pudessem congregar todos os oriundos de uma mesma região ou aldeia. Se várias associações regionais que foram fundadas na década de 30 do século $\mathrm{XX}$ não tiveram condições de sobreviver, as que se criaram no fim dos anos $60 \mathrm{em}$ diante, continuam firmes, tendo bastante projeção na comunidade luso-brasileira, especialmente entre os procedentes da região.

Assim surgiram diversas entidades, como a Casa da Ilha da Madeira (1969), o Arouca São Paulo Clube (1979), a Casa dos Açores (1980), a Associação dos Poveiros de São Paulo (1991), a Casa de Brunhosinho (1991), a Sociedade Gebelinense (1992) e a Casa Cultural Império do Minho (2003), bem como foram construídas diversas igrejas em honra ao santo protetor da aldeia ou região de origem (Nossa Senhora de Fátima, no Sumaré, Nossa Senhora de Fátima, no Imirim, Divino Espírito Santo, em Cerqueira César, Nossa Senhora da Aparecida, na Vila Ida, Santo Ivo, no Ibirapuera, são alguns exemplos).

Cada associação distingue-se por determinado traço que a caracteriza: celebração de festas em datas importantes, como o dia do santo protetor, bem como a recuperação de cerimônias cultivadas no lugar de procedência (entre as quais se destaca a festa do Divino organizada pela Casa dos Açores, um exemplo muito bonito e de muita projeção, caracterizado pela união da comunidade, pela partilha e solidariedade), o cultivo do folclore regional, a divulgação da culinária portuguesa e da aldeia, entre outras características.

As associações regionais são frequentadas por portugueses de várias gerações de camada média, que apreciam se reunir para ouvir as músicas de sua região, acompanhando danças típicas apresentadas pelos muitos ranchos folclóricos fundados tanto para evocar as tradições da terra de origem, como propiciar às novas gerações, em geral plenamente integradas na cultura brasileira, a oportunidade de conhecer e vivenciar diversos aspectos do país e da cultura de seus pais e avós. Os frequentadores das associações regionais conhecem as instituições de maior projeção, mas preferem ficar no ambiente a que estão mais acostumados, no seu bairro e na sua associação. É como se tivesse se estabelecido uma espécie de "trato", 
pelo qual cada um respeita o espaço do outro e quer o seu respeitado. Às festas comemorativas costumam comparecer tanto os associados da entidade promotora do evento como os membros das outras instituições regionais, que são sempre convidados. Por esse motivo, procuram estabelecer um calendário das festividades que não coincida com as datas das outras associações.

Mas agora, depois de passados vários anos, uma questão importante está preocupando os responsáveis pelas associações regionais: é a continuidade do trabalho desenvolvido por essa primeira geração de imigrantes oriundos de diversas regiões portuguesas. Essas associações foram fundadas e sedimentadas à custa de muito esforço e com as doações arrecadadas, muitas vezes conseguidas batendo de porta em porta para solicitar contribuições não só dos membros da comunidade como também dos amigos e vizinhos.

Por outro lado, encontram-se também em São Paulo as grandes instituições que representam a comunidade portuguesa e seus descendentes como um todo. Entre elas contam-se a Sociedade Portuguesa de Beneficência (1859), a Sociedade Beneficente Vasco da Gama (1898), o Centro Trasmontano (1935) - sendo as três entidades atuantes com grande sucesso na área de saúde -, a Câmara Portuguesa Portugal-Brasil (1912), a Associação Portuguesa de Desportos (1920) (esta frequentada por quase toda a comunidade), o Clube Português (1920), a Casa de Portugal (1935), o Lar da Provedoria (1978), o Grêmio Luso-Brasileiro de São Paulo (1980) e o Conselho da Comunidade Luso-Brasileira (1981). No caso dessas instituições, a frequência já é mais elitizada, atraindo portugueses e seus descendentes pertencentes às camadas sociais superiores.

Em relação às entidades de caráter mais geral, a questão não se coloca, pois contam com recursos próprios, principalmente, mas as instituições de caráter regional estão a ver-se com um problema sério atualmente. As novas gerações não estão muitas vezes dispostas a trabalhar em prol da comunidade e da entidade criada por seus pais. Isso exigiria muito esforço sem grande retorno. Os mais velhos têm sua própria visão daquilo que essas entidades devem oferecer a seus associados e conterrâneos, o que não vai ao encontro das aspirações da juventude atual. Os clubes esportivos oferecem geralmente uma gama maior de atividades que atraem mais esses jovens. Por outro lado, as gerações mais antigas, as fundadoras propriamente ditas, hesitam em passar a direção para as mãos dos jovens, na incerteza de que estes estarão dispostos a dispender esforços e tempo para levar avante o ideal, que é mais dos imigrantes do que daqueles que já nasceram no Brasil e sentem que sua pátria está aqui e não do outro lado do Atlântico. Amam Portugal, por aquilo que seus pais lhes contam, gostam até de visitar a região de onde seus antepassados procedem, mas suas raízes estão no Brasil, seus amigos, seu trabalho, seus costumes, as imagens e os apelos 
mais fortes estão neste país. Os imigrantes da primeira geração já estão desaparecendo e tudo o que edificaram está ameaçado de extinção se não forem tomadas medidas mais radicais para sua sobrevivência. Tanto a primeira geração, os imigrantes propriamente ditos, como as subsequentes seus filhos e netos - funcionam como identidades coletivas, usando a linguagem de Corsten (apud DOMINGUES, 2002), cada uma partilhando experiências comuns, dificilmente apropriadas pelas outras, embora em contato e interagindo constantemente. A descontextualização e a recontextualização, que sempre acontecem no caso de migrações, ocorreram mais logo após a chegada, tanto no que se refere ao grupo migrado para o interior do Estado de São Paulo, como em relação àqueles vindos para a cidade de São Paulo. A recontextualização, no primeiro caso, atuou no sentido de propiciar uma mais rápida integração no ambiente em que se instalaram. No segundo caso, a vida próxima a parentes e, posteriormente, a convivência com amigos e conterrâneos dentro das associações levou a um rearranjo com o fortalecimento das tradições de origem e certa adaptação às novas condições de trabalho. $\mathrm{O}$ reforço da identidade coletiva $\mathrm{e}$ étnica aparece também nos nomes de todas as entidades fundadas, que remetem seja a Portugal, seja à região de origem.

As reuniões festivas organizadas periodicamente ainda atraem muitos participantes, mas estes muitas vezes são brasileiros e imigrantes de outras procedências, amantes da culinária portuguesa. Seria muito importante que as diretorias e conselhos das entidades se abrissem para acolher tanto as novas gerações da comunidade luso-brasileira como também as de origem brasileira. Certamente isso contribuiria para a manutenção das associações e instituições, ainda que com traços distintos daqueles que foram impressos por seus fundadores. A integração de vários grupos contribuirá, sem dúvida, para que todo o esforço empreendido por pessoas corajosas e denodadas não se perca por falta de continuadores.

Assim, viu-se que a identidade portuguesa no interior de São Paulo já na primeira geração começou a apresentar certa ambiguidade e a se diluir de certa forma, enquanto na capital paulista ela se manteve mais forte para toda a primeira geração de imigrantes portugueses. Foi o advento da segunda geração e, atualmente, da terceira que começou a pôr em xeque todo o arcabouço das tradições portuguesas transmitidas e de sua identidade, diante da forte integração dos mais jovens na sociedade brasileira. Marieta de Moraes Ferreira enfatizou a estreita correlação entre identidade e identidade coletiva e a memória. Este estudo comprovou que, enquanto a primeira geração vinda para as zonas urbanas tem uma memória viva da região de procedência, reconhece sua identidade como portuguesa, o que vai passando à medida que as novas gerações vão nascendo já no país que seus pais adotaram para viver. É por isso que os imigrantes tentam de todos os modos manter vivas as tradições portuguesas, especialmente com a criação dos 
ranchos folclóricos, onde os jovens podem se apresentar. Em algumas entidades, isso parece estar tendo sucesso, como na Associação Gebelinense. Em outras, não. Não há dúvidas de que no Brasil, nas novas gerações da comunidade luso-brasileira houve uma reconfiguração da identidade étnica, com a adoção de tradições e comportamentos brasileiros pelos descendentes dos imigrantes, mas formando identidades coletivas nas diferentes gerações. São identidades culturais, segundo Boaventura Souza Santos, mesmo verificando-se falta de uma identidade coletiva portuguesa entre aqueles oriundos de aldeias isoladas e comunidades rurais. Mas não falta, de maneira alguma, uma identificação com a região de origem e o sentimento de se sentir em casa quando se reúnem com os patrícios e rememoram e comemoram as tradições locais.

\section{REFERÊNCIAS BIBLIOGRÁFICAS}

ALBUQUERQUE, Rosana de Lemos de Sousa. Associativismo, capital social e mobilidade. 2008. 566f. Tese (Doutoramento em Sociologia das Migrações) - Universidade Aberta de Lisboa, Lisboa.

ARAÚJO FILHO, José Ribeiro. Café, riqueza paulista. Boletim Paulista de Geografia,

Paulo, n. 23, jul. 1956.

BERTAUX, Daniel. L' approche biographique: sa validité méthodologique, ses potentialités. Cahiers Internationaux de Sociologie. Paris, v. LXIX, ano 27: 197-225, juil/déc. 1980.

BOURDIEU, Pierre. La distinction. Critique sociale du jugement. Paris: Les Éditiions du Minuit, 1979.

CAMARGO, José Francisco de. Crescimento da população no Estado de São Paulo e seus aspectos econômicos. São Paulo: Instituto de Pesquisas Econômicas, 1981, 3 v.

CAMPOS, Maria Christina Siqueira de Souza. Imigração e desenvolvimento regional: um estudo sobre os portugueses no meio rural paulista na primeira metade do século XX. 2002. 264f. Tese (Livre-docência em Economia e Ciências Sociais) - Faculdade de Economia, Administração e Contabilidade de Ribeirão Preto, Universidade de São Paulo, Ribeirão Preto.

; LUNARDELO, Paulo Henrique. Portugueses no meio rural paulista (1900-1950). História Oral, São Paulo, ABHO, n. 6, p. 107-131, jun. 2003.

CARREIRAS, H.; MALAMUD, A. Associações portuguesas, integração social e identidades colectivas: o caso do Uruguai. In: MELO, D.; SILVA, E. C. da (Orgs.). A construção da nação e o fenómeno associativo na diáspora portuguesa: perspectivas comparadas. Lisboa: Imprensa de Ciências Sociais (no prelo). p. 97-123 (cap. 3).

DEAN, Warren. Rio Claro: um sistema de grande lavoura. 1820-1920. Rio de Janeiro: Paz e Terra, 1977.

DOMINGUES, José M. Gerações, modernidade e subjetividade. Tempo Social, São Paulo, 14(1): 67-89, maio 2002. 
ENGERMAN, Stanley; NEVES, João César das. The bricks of an empire. 1415-1999. 585 years of Portuguese emigration. The Journal of European Economic History, Roma, v. 26(3), p. 471510, Winter, 1997.

FERREIRA, Marieta de Moraes. História Oral, comemorações e ética. Projeto História. Ética e História Oral, São Paulo, n. 15, p. 157-164, abr. 1997.

FISS, R. L. R. S. B. A imigração portuguesa e as associações como forma de manutenção da identidade lusitana: sul do Brasil. Scripta Nova. Revista Electrónica de Geografía y Ciencias Sociales. Barcelona: Universidad de Barcelona, n. 94 (27), p. 1-17, $1^{\circ}$ ago. 2001. Disponível em: http://www.ub.edu/geocrit/sn-94-27.htm Acesso em: 13 maio 2014.

HARTFIEL, Günter. Wörterbuch der Soziologie. Stuttgart: Alfred Kröner, 1972.

LEITE, Joaquim da Costa. O Brasil e a emigração portuguesa (1855-1914). In: FAUSTO, Boris (Org.). Fazer a América. São Paulo: EDUSP, 1999. p. 177-200

LANG, Alice Beatriz da Silva Gordo; CAMPOS, Maria Christina Siqueira de Souza; DEMARTINI, Zeila de Brito Fabri. História oral e pesquisa sociológica: a experiência do CERU. São Paulo: Humanitas/CERU, 1998.

LOBO, Eulália Maria Lahmeyer. Portugueses en Brasil en el siglo XX. Madri: Mapfre, 1994. Imigração portuguesa no Brasil. São Paulo: Hucitec, 2001.

MARANDOLA JUNIOR, Eduardo; DAL GALLO, Priscila Marchiori. Ser migrante: implicações territoriais e existenciais da migração. Revista Brasileira de Estudos de População, São Paulo, v. 27, n. 2, jul./dez. 2010. Disponível em: http://www.scielo.br scielo.php?script=sci_arttext\&pid $=$ S0102-30982010000200010. Acesso em: 9 jul. 2014.

MARTINS, José de Souza. O cativeiro da terra. $3^{\text {a }}$ ed. São Paulo: Hucitec, 1986.

MERLOTTI, Elzimar Aparecida; CAMPOS, Maria Christina Siqueira de Souza. A contribuição dos imigrantes portugueses para a economia da região de Ribeirão Preto. Cadernos $C E R U$, São Paulo, CERU/Humanitas, série II, $\mathrm{n}^{\circ}$ 13, p.73-98, 2002.

NÓVOA, António Manuel Seixas Sampaio da. Os professores e sua formação. Lisboa: Dom Quixote, 1992.

POLLAK, Michel. "Memória e Identidade social". Estudos Históricos. Rio de Janeiro, CPDOCFGV, 5(10), 1992.

QUEIROZ, Maria Isaura Pereira de. Cultura, sociedade rural, sociedade urbana no Brasil. Rio de Janeiro: LTC/São Paulo: EDUSP, 1978.

ROCHA-TRINDADE, Maria Beatriz. Recriação de identidades em contextos de migração. In: LUCENA, Célia Toledo; GUSMÃO, Neusa Maria Mendes de. (Orgs.). Discutindo identidades. São Paulo: Humanitas/CERU, 2006. p. 75-90.

A serra e a cidade: o triângulo dourado do regionalismo. Lisboa: Âncora, 2009.

SANTOS, Boaventura de Sousa. Pela mão de Alice: o social e o político na pós-modernidade. $8^{\text {a }}$ ed. Porto: Afrontamento, 1994. Publicado também em São Paulo pela Cortez, 1995 (12 ed.). 
SANTOS, Myrian Sepúlveda dos. Sobre a autonomia das novas identidades coletivas: alguns problemas teóricos. Revista Brasileira de Ciências Sociais, São Paulo, v.13, n. 38, 1998. Disponível em: http://dx.doi.org/10.1590/S0102-69091998000300010. Acesso em: $1^{\circ} \mathrm{fev}$. 2012.

STOLCKE, Verena. Cafeicultura: homens, mulheres e capital (1850-1980). São Paulo: Brasiliense, 1986. 